taken. Employed with proper care, total hip replacement arthroplasty is now the treatment of choice for many sufferers from hip disease.

1 Charnley, J., Fournal of Bone and foint Surgery, 1972, 54B, 61.

2 Girdlestone, G. R., Proceedings of the Royal Society of Medicine, 1945,

38, 363.
3 Batchelor, J. S., Proceedings of the Royal Society of Medicine, 1945, 38, 689.

Smith-Petersen, M. N., Journal of Bone and Foint Surgery, 1939, 21, 269.

5 Law, W. A., Fournal of Bone and foint Surgery, 1962, 44A, 1497,

- Law, W. A., fournal of Bone and foint Surgery, 1962, 44A, 1497.

7 Thompson, F. R., fournal of Bone and foint Surgery, 1954, 36A, 489.

7 Thompson, F. R., Fournal of Bone and foint Surgery, 195

- Charnley, J., fournal of Bone and foint Surgery, 1960, 42B, 28

10 McKee, G. K., and Watson-Farrar, J., fournal of Bone and foint Surgery, 1966, 48B, 245.

11 Charnley, J., Lancet, 1961, 1, 1129.

12 Peebles, D. J., Ellis, R. H., Stride, S. D. K., and Simpson, B. R. J., British Medical fournal, 1972, 1, 349.

1s Ring, P. A., fournal of Bone and foint Surgery, 1968, 50B, 720.

\section{Auditory Inattention}

Patients with certain cerebral lesions may have normal fields of vision, normal hearing in each ear, and normal sensation in the limbs tested individually, and yet when bilateral visual, auditory, painful, or tactile stimuli are presented to the patient simultaneously he may recognize a stimulus only on one side, and consistently so. This phenomenon has variously been termed inattention, ${ }^{1}$ extinction, ${ }^{2}$ suppression, ${ }^{3}$ perceptual rivalry, ${ }^{4}$ or neglect, ${ }^{5}$ preceded by the adjective appropriate to the stimulus tested-for example, visual inattention.

H. Oppenheim ${ }^{6}$ described the phenomenon at the end of the last century. J. Babinski, ${ }^{5}$ before the first world war, extended the concept of unilateral neglect to positive denial of disability, such as denial of hemiplegia, and he called the condition anosognosia. Between 1945 and 1953 inattention or extinction was extensively studied, described, and argued about by M. B. Bender and various associates ${ }^{2} 8$ and by Macdonald Critchley. ${ }^{1} 9$ From their work it appeared that from the strictly practical point of view the condition was usually, though not invariably, a sign of a parietal lobe lesion, and it is of course much easier to demonstrate the sign in patients with lesions of the non-dominant hemisphere, whose speech and ability to comprehend are intact, than when the dominant hemisphere is affected. Many of the earlier conclusions about the localization of the lesion relied either on a clinician's judgement or on post-mortem findings, and in general most attention was paid to visual and tactile inattention. Auditory inattention had, however, been described by Oppenheim, 1 and in more detail by $M$. B. Bender and S. P. Diamond, 1011 and D. Denny-Brown and his colleagues. ${ }^{4}$ Again a lesion localized in the parietal lobe was postulated, not invariably with objective confirmation.

Now K. M. Heilman and E. Valenstein ${ }^{12}$ have described 17 cases showing auditory neglect, all of whom were studied by technetium-99 rectilinear brain scanning. Each patient had had some auditory stimulus presented to each ear individually and been shown not to have loss of auditory acuity. Various stimuli were then presented bilaterally and simultaneously by the simple processes of snapping fingers, jingling coins, or placing a stethoscope in the patient's ears and tapping on the diaphragm. The patients consistently identified the sound on one side only. Ten of the 17 had positive brain scans owing to neoplasm or infarction, and nine of these showed lesions in the right inferior parietal area. One lesion was in the left posterior frontal zone. The patients all showed the other forms of sensory inattention as well.
This is not by any means a new test, but it is interesting to correlate investigation of the phenomenon by modern techniques with the older conclusions about the most usual site of the lesion, sometimes deduced, but not proved. These tests are simple to perform and yet not often carried out. The discovery of any of these forms of inattention or neglect makes one strongly suspect a parietal lobe lesion, even in the absence of other forms of so-called "cortical" sensory disturbance. The phenomenon has been found in lesions at other sites, however, and, though valuable, it should not by itself be considered to be of absolute localizing significance.

1 Critchley, M., Brain, 1949, 72, 538.

2 Bender, M. B., Archives of Neurology and Psychiatry, 1945, 54, 1.

3 Furmanski, A. R., Archives of Neurology and Psychiatry, 1950, 63, 205.

4 Denny-Brown, D., Meyer, J. S., and Horenstein, S., Brain, 1952, 75, 433.

5 Babinski, J., Revue Neurologique, 1914, 22, 845 .

6 Oppenheim, H., Neurologisches Zentralblatt, 1885, 4, 529.

7 Bender, M. B., and Furlow, L. T., Archives of Neurology and Psychiatry, 1945, 53, 29.

${ }^{8}$ Bender, M. B., Fink, M., and Green, M., Archives of Neurology and Psychiatry, 1951, 66, 355.

9 Critchley, M., The Parietal Lobes. London, Arnold, 1953.

10 Bender, M. B., and Diamond, S. P., Brain, 1965, 88, 675.

1 Diamond, S. P., and Bender, M. B., Transactions of the American Neurological Association, 1965, 90, 154.

12 Heilman, K. M., and Valenstein, E., Archives of Neurology, 1972, 26, 32.

\section{Heart Operations Followed Up}

Recently we have become so accustomed to truly dramatic developments in cardiac surgery that it is sometimes hard to believe that it all started only 25 years ago. The publication ${ }^{1}$ by Helen Taussig of long-time observations on the first 1,037 cyanotic patients operated upon by Dr. Blalock and his associates between 1945 and 1951 has therefore not only considerable intrinsic interest but helps to put this remarkable work into perspective.

Apart from patients in whom the diagnosis was in doubt and those who had operations other than a Blalock-Taussig anastomosis, 728 patients with tetralogy of Fallot were treated, with a $10 \%$ surgical mortality, and $81.7 \%$ of them were judged to have had an excellent or good immediate result. Most of the patients were children, the peak in the age distribution curve being between 2 and 5 years. The scatter was wide, however, and there were 17 among those aged under 1 and over 25 years. Mortality was highest under the age of $2(27 \cdot 4 \%)$ but only $6.5-7 \%$ between the ages of 6 and 14 years.

Because patients travelled from far and wide to Baltimore seeking treatment, long-term assessment has not been easy, and Dr. Taussig and her colleagues have gone to great lengths to achieve a 93\% 10-year and an $88 \%$ 15-year follow-up of the 685 cases who left hospital alive two months after their first operation. Year-by-year analysis shows a relatively high mortality rate between 3 and 11 months after operation; thereafter it was remarkably constant. Though 209 patients had second operations within 15 years, the majority because of failure to maintain improvement, 313 were living on their first anastomosis 15 years later. It is of considerable interest that losses in the latter group were at a lower rate than the $30 \%$ surgical mortality combined with the late mortality in the group who had further operations. The results of all types of heart surgery have steadily improved with practice (Blalock's mortality rates fell from $20.3 \%$ in 1945 to $4.7 \%$ in 1951), 
but these figures do suggest that sometimes it is still wise to leave well alone.

The age of the patient at the time of the first operation greatly influenced the need for further surgery; $60 \%$ of those under 2 years and only $31 \%$ of those between 10 and 14 years required a second operation. As might be expected, the number of second operations gradually increased as the time interval from the first operation increased. The evidence also suggests that the need for a second operation was delayed in younger patients (2-14 years) if the subclavian-pulmonary end-to-side anastomosis was performed on the side opposite the aortic arch.

Only 29 of the 685 who survived the first shunt were known to have developed pulmonary hypertension. As might be expected this complication was relatively much commoner in patients with large shunts through Potts or innominate anastomoses than it was in those whose subclavian artery had been used, thus limiting the increased flow of blood through the lungs.

Apart from complications related to surgical procedures, this long-term survey of so large a group as 779 cases of Fallot's tetralogy yields valuable information about other complications traditionally associated with severe cyanotic congenital heart disease. Tuberculosis, for example, to which all such patients were once considered extremely susceptible, was found only twice before and eight times after operation. But two other infections lived up to their reputations and emerge as major causes of disease and death. Brain abscess, always a worrying possibility with its problems of diagnosis and treatment, occurred in 38 and was suspected in another 5 -an incidence of $5.5 \%$. Even in the 25 in whom it was diagnosed and treated surgically the mortality rate was $40 \%$, and the importance of early diagnosis and prompt drainage is emphasized. Perhaps the most surprising feature of the whole investigation is the remarkably high incidence $(14.3 \%)$ of subacute bacterial endocarditis. No fewer than 112 of the 779 patients were treated for this complication; 24 of them died-a mortality rate of $21.4 \%$. In only eight instances was the infection related to the surgical operation. Positive cultures were obtained in 71 patients, and, though Streptococcus viridans was the commonest organisn to be isolated (43 cases), a staphylococcus was isolated in 22. These natural complications, essentially uninfluenced by the success or failure of palliative surgery, are powerful arguments in favour of complete repair if this can be achieved with a lesser mortality.

On a happier note, it is gratifying to see that 125 of the women and 95 of the men had married and produced 196 children, only three of whom had congenital cardiac malformations. In assessing their patients' other achievements the investigators were hamnered by the fact that only 180 of the 600 patients supplied the relevant information. Whether this indicates reticence or pride is not known, but of those who did talk of their success 53 had reached the top professional bracket of doctors, lawyers, ministers, teachers, or nurses. Moreover, two-thirds of them were living on their first anastomosis at the time, with arterial oxygen saturations of between $66 \%$ and $85 \%$, thus proving that sustained arterial desaturation over a period of 10 to 20 years does not cause serious mental retardation and that severe physical handicap in childhood need not preclude success in adult life.

1 Taussig, H. B., et al., fohns Hopkins Medical fournal, 1971, 129, 243,258 , and 274 .

\section{Condylomata Acuminata}

In 1949 M. J. Strauss and colleagues ${ }^{1}$ showed by electronmicroscopy that skin warts contained papilloma virus. In the last few years research on the subject of genital and anal warts, often termed condylomata acuminata, has been revived by further electron-microscope studies.

J. D. Oriel and J. D. Almeida ${ }^{2}$ found intranuclear papilloma virus particles in thin sections of a vulval wart, and by a negative staining technique such particles were also identified in 13 out of 25 genital warts examined. In 1971 Oriel $^{3}$ reported on 332 patients (191 men and 141 women) with genital warts. He noted that in many ways genital warts behaved like a sexually transmitted disease with the age of onset closely parallel to that of gonorrhoea. Warts appeared at the genital sites most often injured during coitus and were exacerbated by pregnancy, and he noted a high incidence of genital warts among the sexual contacts of patients. Though some patients with skin warts had genital warts of the same distinctive appearance (verruca vulgaris), he found no epidemiological evidence of a close relationship between genital and skin warts. Thus it seemed possible that though skin warts could be inoculated on to the genitals, either as an autoinoculation or non-sexually from another individual, the common transfer of genital warts was by sex contact, and that this type of wart was not capable of inoculation on to the general skin surface. Some immunity studies supported this "one way" phenomenon.

More recently Oriel ${ }^{4}$ has directed his attention to anal warts. He pointed out that the Romans were aware that the "fig-like" anal warts resulted from anal intercourse and he quoted Martial writing in the 1st century A.D.:

"In order to buy some slave boys

Labienus sold his gardens;

But now poor Labienus has

Only an orchard of figs."

He studied 72 men and 8 women with this condition. Sixty $(83 \%)$ of the men and 5 of the women admitted anal intercourse before the appearance of the warts. Only limited tracing of sexual contacts was possible, but he was unable to obtain much evidence of sexual infectivity. In a retrospective study of 500 homosexual males he found anal warts to be seven times commoner than penile warts, and he suggested there might be some traumatic factor in the development of the anal warts. However, since the incubation period of condylomata acuminata may be as long as one year or longer, this study does not exclude the possibility that anal warts are usually sexually transmitted.

The clinician has to differentiate anal warts from the condylomata lata of the secondary stage of early syphilis, and to remember also that these two sexually transmitted conditions may occasionally occur together in the same patient. In fact it is his duty to look for all the other sexually transmitted diseases, since both gonorrhoea and trichomoniasis, by producing purulent genital discharges, may exacerbate genital warts whether under the prepuce in men or on the vulva in women. It was this association of diseases which produced the misnomer in the past of "gonorrhoeal warts." It is also most important to differentiate between anal warts and carcinoma, especially as warts can themselves rarely become malignant. Such a case was decribed by Oriel and I. W. Whimster. ${ }^{5}$

The treatment of condylomata acuminata depends on the 